\title{
A new child-friendly 3D bimanual protocol to assess upper limb movement in children with unilateral Cerebral Palsy: development and validation
}

\section{Authors}

Marine CACIOPPO a,b,c, Antoine MARIN ${ }^{\mathrm{d}}$, Hélène RAUSCENT ${ }^{\mathrm{a}}$, Estelle LE PABIC ${ }^{\mathrm{e}}$, Florence GAILLARD $^{\mathrm{d}}$, Sylvain BROCHARD ${ }^{\mathrm{b}, \mathrm{c}, \mathrm{f}}$, Ronan GARLANTEZEC ${ }^{\mathrm{g}}$, Armel CRETUAL ${ }^{\mathrm{d}}$, Isabelle BONAN ${ }^{\mathrm{a}, \mathrm{h}}$.

a. Department of Physical Medicine and Rehabilitation, Rennes University Hospital, 35033 Rennes, France

b. Pediatric Rehabilitation Department, Fondation ILDYS, 29200 Brest, France

c. Laboratoire de Traitement de l'information Médicale (LaTIM), Inserm U1101, Université de BretagneOccidentale, 29200 Brest, France

d. M2S laboratory (Mouvement Sport Santé), Rennes 2 University - ENS Rennes - UEB, Campus de Ker Lann, 35170 Bruz, France

e. CIC Inserm 1414. Centre d'Investigations Cliniques, Rennes University Hospital, 35033 Rennes, France

f. Department of Physical Medicine and Rehabilitation, Brest University Hospital, 29200 Brest, France

g. Department of Public Health, Rennes University Hospital, 35033 Rennes, France

h. Unité Empenn (ex-Visages) U1228 INSERM-INRIA, IRISA UMR CNRS 6074, Campus de Beaulieu, 35042 Rennes Cedex, France

Keywords: Unilateral cerebral palsy; three-dimensional motion analysis; upper limb; bimanual task; movement quality

Corresponding author: Marine Cacioppo $\underline{\text { marine.cacioppo@sfr.fr }}$ 


\section{ABSTRACT}

Unilateral cerebral palsy ( $\mathrm{uCP}$ ) causes upper limb movement disorders that impact on daily activities, especially in bimanual condition. However, a few studies have proposed bimanual tasks for 3D motion analysis. The aim of this study was to validate the new version of a child-friendly, 3D, bimanual protocol for the measurement of joint angles and movement quality variables. Twenty children with uCP and 20 typically developing children (TDC) performed the five-task protocol integrated into a game scenario. Each task specifically targeted one or two upper limb degrees of freedom. Joint angles, smoothness and trajectory straightness were calculated. Elbow extension, supination, wrist extension and adduction amplitudes were reduced; hand trajectories were less smooth and straight in children with uCP compared to TDC. Correlations between the performance-based score and kinematic variables were strong. High within and between-session reliability was found for most joint angle variables and lower reliability was found for smoothness and straightness in most tasks. The results therefore demonstrated the validity and reliability of the new protocol for the objective assessment of bimanual function in children with uCP. The evaluation of both joint angles and movement quality variables should increase understanding of pathological movement patterns and help clinicians to optimize treatment.

\section{ClinicalTrials.gov identifier: NCT03888443}




\section{INTRODUCTION}

3D motion analysis (3DMA) is increasingly used to objectively quantify UL movement in children with uCP (Jaspers et al., 2009), both to increase understanding of movement disorders and to evaluate treatment effectiveness. However, there is currently no consensus regarding the most appropriate tasks or variables to evaluate in order to provide a global description of UL movement. Unimanual reaching or grasping tasks are frequently used because they are simpler to analyse than bimanual tasks, however they do not reflect reallife since most daily life activities involve the collaborative use of both hands (Butler et al., 2010b; Hung et al., 2012; Jaspers et al., 2011a). To date, only a few studies have proposed bimanual tasks for 3DMA, but their psychometric properties have not been analysed (Hung et al., 2004; Hung and Spingarn, 2018; Klotz et al., 2014; Rudisch et al., 2016). Furthermore, although many studies of children with uCP have evaluated joint angles and spatiotemporal parameters (i.e. velocity, movement duration, etc.) (Butler et al., 2010a; Hung et al., 2004; Jaspers et al., 2011a; Mailleux et al., 2017; Rudisch et al., 2016), few have evaluated smoothness (movement regularity) and trajectory straightness (the extent to which the movement is performed directly in a straight line without deviations), particularly during bimanual tasks, despite the fact these variables are important indicators of movement quality (Butler et al., 2010a; Jaspers et al., 2011a; Mailleux et al., 2017).

In order to provide an overall assessment of UL movement in children with $\mathrm{uCP}$, a 3D bimanual protocol called 'Be An Airplane Pilot' (BE-API) was developed with standardized tasks integrated into a game scenario (Bouvier et al., 2019; Gaillard et al., 2019). The protocol aimed to explore all the degrees of freedom (DoF) of the impaired UL known to be limited in children with $\mathrm{uCP}$ by encouraging and analysing movements in functional amplitudes. The protocol was found to be reliable for the evaluation of some kinematic parameters but it had several drawbacks: (1) none of the tasks specifically explored shoulder elevation or wrist extension; (2) the protocol was assessed in a few children with severe motor deficits and was thus not representative of all the children who could perform the protocol; and (3) there was no evaluation of variables relating to movement quality. An updated version of the BE-API, the BE-API 2.0, was thus developed to address these limits, with new tasks to ensure that all UL DoF were evaluated.

The aims of this study were therefore to assess the validity and reliability of the BE-API 2.0, including (1) content validity by verifying that the DoF of interest for each task were largely mobilized compared to the 
other DoF, (2) discriminative ability through comparison with typically developing children (TDC), (3) construct validity, through analysis of the relationship between 3DMA variables and a clinical evaluation of bimanual performance and (4) reliability including within and between-session reliability.

\section{METHODS}

\subsection{Participants}

In this prospective, case-control study, twenty children with $\mathrm{uCP}$ were recruited from the Physical Medicine and Rehabilitation Department of Rennes University Hospital (France) between February and June 2019. Inclusion criteria: children aged from 6 to 17 years, with sufficient grasp ability to perform the protocol tasks (MACS (Manual Ability Classification System) level I to III (Eliasson et al., 2006)). Exclusion criteria: severe cognitive or visual disturbances, UL pain, previous UL surgery, and botulinum toxin injections less than three months prior to participation. Twenty age matched, typically developing children (TDC) were included for comparison (Supplementary Material 1). One child with uCP did not complete the protocol and his data were excluded from the analysis (Supplementary Material 2).

Approval for this study was obtained from the ethical committee Ouest II of Angers (accepted 04/02/2019, $\left.\mathrm{N}^{\circ} 2019 / 05\right)$. All parents and children received oral and written information about the study before participating.

\subsection{BE-API 2.0 protocol}

The BE-API 2.0 protocol consisted of 3D motion analysis of UL movements during five "flying missions" using a game set-up (2-handed joystick, turbo, shifter, dashboard, box and buzzer) placed on a table. Each "flying mission" involved a bimanual task specifically designed to explore either one or two DoF that are typically limited in children with uCP (Coluccini et al., 2007; Fitoussi et al., 2006; Mackey et al., 2006), named DoF of interest: task 1 "flying over mountains" = elbow extension and wrist adduction (Video 1), task 2 "slaloming" = shoulder rotations (video 2), task 3 "hooking the luggage" = shoulder elevation and humeral plane of elevation (Video 3), task 4 "opening the door" = wrist extension (Video 4) and task 5 "refuelling" = elbow supination (Video 5). Of these 5 tasks, Task 3 "hooking the luggage on dashboard" and Task 4 "opening the door" were developed for this new version of BE-API, with two new objects (the dashboard 
and the shifter), in order to explore the DoF that were not specifically mobilized in the previous version. Tasks $2,3,4$ and 5 were asymmetrical, i.e. the movement of interest was only performed by the impaired (non-dominant) UL while the dominant UL was involved in a different, simultaneous movement. The BEAPI 2.0 protocol is fully detailed in Table 1 .

The starting position for each task was upright sitting on an adjustable chair with $90^{\circ}$ of hip, knee and elbow flexion. The forearm and hand were positioned on the table.

In order to facilitate immersion in the playful scenario, the decor was improved compared to the first version of BE API with the projection of a slide show (images or photographs according to the participant's age) for each "mission" on a screen in front of the participant.

\subsection{Motion capture and data processing}

Data were collected with a 10-camera VICON® system at a sampling frequency of $100 \mathrm{~Hz}$ (Oxford Metrics, UK). Twenty-six 9mm reflective markers were applied to the trunk, arms, forearms and hands according to the International Society of Biomechanics (ISB) recommendations (Wu et al., 2005). Trunk (lateral-flexion, flexion-extension and rotations), shoulder (rotations, elevation and humeral plane of elevation), elbow (flexion-extension and pronation-supination), and wrist (flexion-extension and abduction-adduction) angles were calculated using the Euler sequences recommended by the ISB (Wu et al., 2005). The shoulder joint was defined as the "thoracohumeral joint" and its centre was estimated using a functional method (Lempereur et al., 2010). All data were processed with Matlab® (MathWorks, Natick, MA, USA).

Participants performed 5 consecutive movement repetitions (5 trials) each of tasks $1-4$ at their own selfselected speed. At the end of the 5 trials of a given task, 1 trial of task 5 "refuelling" was performed in order to maintain a playful link between tasks. Task 5 was thus performed four times, at the end of each of the other tasks. The chronological order of a session was: Task 1 (four trials) - Task 5 (one trial) - Task 2 (four trials) - Task 5 (one trial) - Task 3 (four trials) - Task 5 (one trial) - Task 4 (four trials) - Task 5 (one trial). For tasks 1, 2, 3 and 4, the first trial was ignored as a training trial, thus four trials of each task (4 trials $\mathrm{x} 5$ tasks) were analysed. For each DoF and each task, the mean value of the 4 trials was calculated for each variable. 
Sessions lasted around 30 minutes: positioning of markers and set-up (10 minutes), explanation (5 minutes), 3D acquisition (10 minutes) and removal of markers (5 minutes). All sessions were performed under exactly the same conditions by each participant.

\subsection{Study schedule}

For the uCP group, the inclusion visit was either scheduled during a routine consultation or was carried out by telephone. For the TDC group, it was carried out by telephone. Visits 1 and 2 (uCP group only) were scheduled 2 to 4 weeks apart with the same assessor for the evaluation of between-session reliability.

\subsection{Kinematic variables and clinical assessment}

The use of each variable for the evaluation of validity or reliability is shown in Supplementary Material 8.

\subsubsection{Kinematic variables}

The following angle-related variables were calculated for each DoF for each task:

- Maximum angle value (MAX)

- Range of motion (RoM) (maximum-minimum angle value during a trial)

- The Arm Profile Score (APS): a kinematic index that reflects the total deviation of the UL movement during each task (angular values) developed by Jaspers et al. (Jaspers et al., 2011d). It was calculated as the root mean square error average of the 10 joint movements (thorax, shoulder, elbow, wrist) during each task and compared to the TDC group (see Supplementary Material 9). The global-APS was calculated by averaging the APS values for the five tasks.

Two movement quality variables were evaluated from the displacement of the wrist joint centre:

- Smoothness was calculated by the spectral arc length (SPARC), from the measurement of changes on the Fourrier spectrum, providing a negative value (Balasubramanian et al., 2015, 2012). This method was chosen for its high accuracy. Higher SPARC values indicate smoother movement.

- Trajectory straightness was evaluated using the index of curvature (IoC) (Butler et al., 2010a; Jaspers et al., 2011c). The IoC corresponds to the distance travelled by the hand divided by the linear distance between the start and stop position; therefore, an IoC of 1 indicates a straight trajectory. The IoC 
was only calculated for the two unconstrained tasks (tasks 3 and 5) during which participants did not hold a fixed object (e.g. the 2-handed joystick or shifter).

\subsubsection{Clinical assessment}

The Assisting Hand Assessment (AHA) (Krumlinde-Sundholm et al., 2007), a performance-based measure of bimanual activities, was only assessed in the uCP group on Visit 1. Children first performed a video-recorded play session and then a trained occupational therapist scored their performance on the 22 items using a 4-point criterion-referenced rating scale. The total score was then converted to AHAunits, where 100 corresponds to a high level of spontaneous use of the impaired hand. The items describe different object-related actions of the assisting hand (Supplementary Material 9). Two items were considered relevant for the evaluation of construct validity in this study: "move your forearm" (pronation-supination) and "flow in bimanual task performance" (movement smoothness).

\subsection{Statistical analysis}

All statistical tests were performed with a two-tailed significance level of $5 \%$ using MATLAB ${ }^{\circledR}$ (MathWorks, Natick, MA, USA) and SAS, v.9.4® (SAS Institute, Cary, NC, USA).

\subsubsection{Validity}

Content validity: Each task was specifically designed to evaluate one or two DoF of interest, by inducing large amplitude movements of those DoF. Tasks were considered to have good content validity if the DoF targeted by the task was one of the $3 \mathrm{DoF}$ with the greatest RoM values during the task.

Discriminant validity: MAX, RoM, SPARC and IoC were compared between the uCP and TDC groups using a repeated measures ANOVA (mixed model). A rank-based model was used when the distribution was not normal.

Construct validity: Relationships between AHA score and APS (APS for each task and global-APS) were calculated for the uCP group. Two specific relationships were analysed: (1) mean MAX and RoM of forearm pronation-supination (task 5) and the "move your forearm" item of the AHA, (2) mean SPARC and IoC for each task and the "smoothness of movement" item of the AHA. Bivariate correlations were calculated using 
Spearman or Pearson's rank correlation coefficients according to the distribution of the data. A correlation coefficient $>0.90$ was considered 'very high', 0.70-0.89 'high', 0.50-0.69 'moderate', 0.30-0.49 'low' and $<0.30$ 'little or no correlation'(Hinkle et al., 2002).

\subsubsection{Reliability}

Within-session reliability was evaluated in the uCP and TDC groups during Visit 1 by comparing the values of the variables for each movement cycle of each task; between-session reliability was only evaluated for the $\mathrm{uCP}$ group (Visits 1 and 2).

The reliability of RoM, MAX, APS, SPARC and IoC data were assessed using the intraclass correlation coefficient $(\operatorname{ICC}(2, \mathrm{k}))$ and classified as 'excellent' $(\geq 0.80)$, 'good' $(0.60-0.79)$, 'moderate' $(0.40-0.59)$, and 'poor' $(<0.40)$. The standard error of measurement (SEM) (Engdahl and Gates, 2019; Jaspers et al., 2011b) was calculated and used to calculate the minimal detectable change (MDC) which is the minimal amount of change that a measurement must show to reflect true change $(\mathrm{MDC}=\mathrm{SEM} X 1.96 \mathrm{X} \sqrt{ } 2)($ Engdahl and Gates, 2019).

\section{RESULTS}

\subsection{Validity}

\subsubsection{Content validity (Fig. 2)}

Five of the seven DoF of interest had the largest amplitudes during the respective tasks. Content validity was thus confirmed for tasks 3, 4, 5; partially for task 1 "Flying over mountains" but not for task 2 "Slaloming". See Fig. 2 for details.

\subsection{Discriminant validity (Table 2)}

\subsubsection{Joint angles: MAX and RoM for the DoF of interest in each task}

Significantly lower values of elbow extension MAX and RoM (task $1, P<0.05$ ), wrist abduction-adduction RoM (task 1, $P<0.05$ ), humeral plane of elevation RoM (task 3, $P=0.005$ ), wrist extension MAX and RoM (task 4, $P<0.005$ ) and pronation-supination MAX and RoM (task 5, $P<0.005$ ) were found in the uCP group compared with the TDC group. 


\subsubsection{Smoothness and trajectory: SPARC and IoC}

SPARC values were significantly lower in the uCP group than the TDC group for task 3 "Hooking the luggage" $(P<0.05)$ but there were no differences for the other tasks. There was a significant between-group difference in the IoC for task $3(P<0.05)$ with less straight movement in the uCP group.

\subsection{Construct validity}

Mean AHA score was 66.95 AHA-units (SD 17.03). AHA score was significantly correlated with APS for each task $(\mathrm{r}=-0.78$ in task $1 ; \mathrm{r}=-0.84$ in task $2 ; \mathrm{r}=-0.76$ in task $3 ; \mathrm{r}=-0.78$ in task 4 and $\mathrm{r}=-0.86$ in task 5 ; $P \leq 0.001)$, and with Global-APS (r=-0.84; $P<0.001)$.

Significantly moderate correlations were found between forearm pronation-supination MAX and RoM (task 5 "Refuelling") and the AHA "move your forearm" item (respectively $\mathrm{r}=0.68$ and $\mathrm{r}=-0.65 ; P<0.005$ ). The SPARC was moderately and significantly correlated with the AHA "smoothness of movement" item in task 3 "Hooking the luggage" $(\mathrm{r}=0.47 ; P<0.05)$ and task 4 "Opening the door" $(\mathrm{r}=-0.53 ; P<0.05)$. The IoC and AHA "smoothness of movement" item in task 3 "Hooking the luggage" were significantly, moderately correlated $(\mathrm{r}=-0.53 ; P<0.05)$.

\subsection{Within and between-session reliability}

\subsubsection{Joint angles (Table 3)}

\subsubsection{MAX and RoM}

For all the DoF of interest, within-session reliability was excellent for both $\operatorname{MAX}(0.88<\mathrm{ICC}<0.99)$ and RoM $(0.85<\mathrm{ICC}<0.98)$ in both groups. The mean MDC for RoM was $5.8^{\circ}\left(2.48<\mathrm{MDC}<9.81^{\circ}\right)$ in the TDC group and $5.94^{\circ}\left(2.19-10.23^{\circ}\right)$ in the uCP group.

In the $\mathrm{uCP}$ group, between-session reliability was excellent for both MAX and RoM for elbow extension, wrist abduction-adduction, wrist extension, pronation-supination, and MAX shoulder elevation $(0.84<\mathrm{ICC}<0.97)$, and was good for the other MAX and RoM values $(0.64<\mathrm{ICC}<0.78)$. The between-session MDC for RoM was $12^{\circ}\left(5.35^{\circ}<\mathrm{MDC}<19.46^{\circ}\right)$.

\subsubsection{Arm Profile Score}


Between-session reliability of the APS was excellent for each task $(0.93<\mathrm{ICC}<0.95)$ and the mean MDC was $5.57^{\circ}\left(5.24^{\circ}<\mathrm{MDC}<5.79^{\circ}\right)$.

\subsubsection{Smoothness and trajectory (Table 4)}

\subsubsection{SPARC}

Within-session reliability of the SPARC was moderate-to-good for tasks 1 and 2 for the TDC group (ICC $=0.72$ and ICC $=0.53$, respectively) and for tasks 1,3 and 4 for the $\mathrm{uCP}$ group $(0.61<\mathrm{ICC}<0.76)$. MDC values were higher for the $\mathrm{uCP}$ than the TDC group for all tasks $(0.33-1.08$ and $0.17-0.80$, respectively).

The between-session reliability of the SPARC was also moderate-to-good in tasks 3 and 4 for the uCP group $(0.57<\mathrm{ICC}<0.84)$. The between-session MDC values were below 0.36, except for task $2(\mathrm{MDC}=0.50)$.

\subsubsection{IoC}

Within-session reliability of the IoC was good for tasks 3 and 5 in both groups $(0.62<$ ICC $<0.77)$. MDC values were lower in task 3 ( 0.22 and 0.69$)$ than in task 5 (4.52 and 2.44) in both groups.

Between-session reliability of the IoC was good for tasks 3 and 5 for the uCP group $(0.61$ and 0.73 , respectively). The MDC values were 0.44 for task 3 and 1.22 for task 5 .

\section{DISCUSSION}

The results of this study showed that the BE-API 2.0 protocol, an innovative, quantitative evaluation of bimanual function, that included movement quality variables had content, discriminative and construct validity, and within- and between-session reliability in a representative sample of children with uCP.

\subsection{Content validity}

Most of the tasks of the BE API 2.0 protocol successfully met the challenge of inducing large amplitude movements of the DoF of interest. Moreover, the child-friendly task design allowed more movement spontaneity than more experimental designs. Importantly, although the BE-API is not composed of activities of daily living, it measured ranges of motion that are functionally relevant to everyday life (Gates et al., 2016). Moreover, the tasks that were newly introduced into the BE-API 2.0 induced larger amplitudes of 
movement in the DoF of interest than the previous version (e.g. MAX shoulder elevation was $112^{\circ}$ versus $68.7^{\circ}$ previously) (Gaillard et al., 2019). Thus the conception of tasks that specifically focused on one or two DoF allowed functional joint amplitudes to be fully explored (Butler et al., 2010b; Hung et al., 2012; Jaspers et al., 2011a). Task 2 "Slaloming" did not induce the expected amplitude of shoulder rotation, probably because of the high proportion of children with MACS level III included in the study. However, task 2 "slaloming" required turning the wheel, which was the most difficult movement of the protocol and thus is useful for exploring joint synergies and compensatory movements (Butler et al., 2010b; Gaillard et al., 2018; Jaspers et al., 2011a; Mailleux et al., 2017).

\subsection{Discriminant validity}

Both RoM and MAX joint angle variables successfully discriminated between the children with uCP and the TDC. The new tasks confirmed that humeral plane of elevation and wrist extension amplitudes were significantly lower in the children with uCP compared to the TDC (Jaspers et al., 2011a; Klotz et al., 2014; Rudisch et al., 2016). The lack of between group differences in shoulder elevation was likely due to scapular compensation for deficits in gleno-humeral elevation (Brochard et al., 2012).

The SPARC and IoC movement quality variables both successfully differentiated between the uCP and TDC groups for task 3 "Hooking the luggage" only. In that task, the hand trajectory was less straight and smooth in the uCP group, as has been found previously for unimanual reaching tasks (Butler et al., 2010a; Jaspers et al., 2011a; Mailleux et al., 2017). It has been demonstrated that during the simultaneous use of both hands, non-symmetrical movement interference could impact on performance (Rudisch et al., 2016). The movement performed in task 3 differed from that in the other tasks because it: 1) was a simple, large amplitude movement, 2) was unconstrained, and thus required more motor control mechanisms (to provide both strength and stability against gravity); and 3) required precision at the start and end of the movement (to grasp the object, then to stabilize and fix it to the top of the dashboard). These results suggest that the SPARC and IoC are useful tools to identify differences between children with $\mathrm{uCP}$ and TDC, provided that an appropriate task is chosen, i.e. one which involves an unconstrained, large amplitude and challenging movement. The addition of such movement quality variables to the usual evaluation of kinematic variables provides a global assessment of upper limb function. 


\subsection{Construct validity}

The BE-API 2.0 protocol was found to have good construct validity, as demonstrated by the strong relationship between the UL kinematic variables and the widely used clinical assessment of bimanual activities, the AHA. This finding was reinforced by the fact that correlations between the AHA and APS were stronger than those reported for unimanual tasks (Gaillard et al., 2018; Mailleux et al., 2017) (respectively $\mathrm{r}=-0.75$ and $\mathrm{r}=-0.49$ ), suggesting that the BE-API 2.0 truly measured bimanual performance. Previous 3DMA studies only explored correlations between the AHA and joint angle variables (Gaillard et al., 2019; Mailleux et al., 2017), this is the first study to integrate movement quality variables. The results of the AHA, a semi-quantitative evaluator-dependent measure, and BE-API 2.0, an objective evaluation, were convergent for both joint angle and movement quality variables. Similarly to the combination of clinical and 3DMA data that is common practice in gait analysis, the AHA and BE-API 2.0 thus appear to be complementary for the assessment of bimanual performance.

\subsection{Reliability}

Reliability of joint angle variables was high for all the DoF of interest (within-session reliability for both groups and between-session reliability for the uCP group). The ICC values calculated were higher than those reported for previous unimanual protocols (Jaspers et al., 2011a, 2011b). With regards to the movement quality variables, the SPARC provided a highly precise calculation of movement smoothness (Balasubramanian et al., 2015, 2012), but it appeared to be very sensitive to the type of movement analysed. To date, the reliability of the SPARC had only been approximately evaluated in children with uCP in unimanual conditions using inertial sensors (Newman et al., 2017). A study of healthy adults performing daily activities found similar within-session reliability (ICC 0.49-0.64) but higher between-session reliability (ICC 0.81-0.84) than the present study (Engdahl and Gates, 2019). Until now, the reliability of the IoC had only been evaluated in children with uCP performing unimanual tasks (Butler et al., 2010a; Schneiberg et al., 2010).

This study thus provides reference data and MDC values for all kinematic variables that can be used in clinical practice and research. Most of the differences in joint angle values between the $\mathrm{uCP}$ and TDC groups were higher than the MDCs for the $\mathrm{uCP}$ group, demonstrating the clinical pertinence of these measures. 
Although the reliability of the APS had already been evaluated, no MDC value had been determined (Jaspers et al., 2011d). The low MDC value $\left(<6^{\circ}\right)$ found for the APS in the present study supports its utility for the assessment of UL movement deviations.

\subsection{Limitations}

The number of subjects to be included was not based on a statistical calculation but was defined according to the feasibility of inclusion. However, this was also the case in similar studies published in the literature (Gaillard et al., 2019; Jaspers et al., 2011b, 2011c; Schneiberg et al., 2010). The relatively small number of participants might have led to the study being underpowered, which could explain some of the low values found. This study was carried out in a single centre with assessors who were welltrained in the use of the BE API 2.0 protocol. A period of training might be necessary to obtain the same level of validity and reliability in other centres, and before it is used in routine practice. In this study, the shoulder girdle was considered as a thoraco-humeral joint, the lack of evaluation of scapular movement is an inherent deficiency of the model.

\subsection{Conclusion}

The results of this large, methodologically rigorous study showed that the BE-API protocol is valid and reliable for the bimanual assessment of UL motor deficits in children with uCP aged from 6 to 18 years and with different levels of impairment. The evaluation of both joint angle and movement quality variables in this protocol could increase understanding of pathological UL movement patterns as well as support clinical decisions and help to determine well-targeted treatment plans. Further studies are now needed to determine the sensitivity to change of the protocol for the assessment of the effectiveness of therapeutic interventions. 


\section{ACKNOWLEDGMENT}

We wish to thank the participants and their families, the team of the Paediatric Physical Medicine and Rehabilitation department of Rennes University Hospital and M2S laboratory. We also thank Johanna Robertson for language assistance and constructive criticism.

This work was supported by the IPSEN Company. They provided financial support for the conduct of the research. They were not involved in study design; in the collection, analysis and interpretation of data; in the writing of the report; and in the decision to submit the article for publication.

\section{CONFLICT OF INTEREST STATEMENT}

Declarations of interest: none 


\section{REFERENCES}

Balasubramanian, S., Melendez-Calderon, A., Burdet, E. A robust and sensitive metric for quantifying movement smoothness. IEEE Trans Biomed Eng 2012;59:2126-2136.

Balasubramanian, S., Melendez-Calderon, A., Roby-Brami, A., Burdet, E. On the analysis of movement smoothness. J Neuroeng Rehabil 2015;12.

Bouvier, B., Gaillard, F., Bouzillé, G., Pasquet, T., Rauscent, H., Bonan, I., Crétual, A. Proposal of a new 3D bimanual protocol for children with unilateral cerebral palsy: Reliability in typically developing children. Journal of Electromyography and Kinesiology 2019;49:102347.

Brochard, S., Lempereur, M., Mao, L., Rémy-Néris, O. The role of the scapulo-thoracic and glenohumeral joints in upper-limb motion in children with hemiplegic cerebral palsy. Clin Biomech (Bristol, Avon) 2012;27:652-660.

Butler, E.E., Ladd, A.L., LaMont, L.E., Rose, J. Temporal-spatial parameters of the upper limb during a Reach \& Grasp Cycle for children. Gait \& Posture 2010a;32:301-306.

Butler, E.E., Ladd, A.L., Louie, S.A., Lamont, L.E., Wong, W., Rose, J. Three-dimensional kinematics of the upper limb during a Reach and Grasp Cycle for children. Gait Posture 2010b;32:72-77.

Coluccini, M., Maini, E.S., Martelloni, C., Sgandurra, G., Cioni, G. Kinematic characterization of functional reach to grasp in normal and in motor disabled children. Gait \& Posture 2007;25, 493-501. https://doi.org/10.1016/j.gaitpost.2006.12.015

Eliasson, A.-C., Krumlinde-Sundholm, L., Rösblad, B., Beckung, E., Arner, M., Ohrvall, A.-M., Rosenbaum, P. The Manual Ability Classification System (MACS) for children with cerebral palsy: scale development and evidence of validity and reliability. Dev Med Child Neurol 2006;48:549-554.

Engdahl, S.M., Gates, D.H. Reliability of upper limb movement quality metrics during everyday tasks. Gait \& Posture 2019;71:253-260.

Fitoussi, F., Diop, A., Maurel, N., Laassel, E.M., Penneçot, G.F. Kinematic analysis of the upper limb: a useful tool in children with cerebral palsy. J Pediatr Orthop B 2006;15, 247-256.

Gaillard, F., Cacioppo, M., Bouvier, B., Bouzille, G., Newman, C.J., Pasquet, T., Cretual, A., Rauscent, H., Bonan, I. Assessment of bimanual performance in 3-D movement analysis: Validation of a new clinical protocol in children with unilateral cerebral palsy. Ann Phys Rehabil Med 2019.

Gaillard, F., Cretual, A., Cordillet, S., Le, C.C., Gonthier, C., Bouvier, B., Heyman, R., Marleix, S., Bonan, I., Rauscent, H. Kinematic motion abnormalities and bimanual performance in children with unilateral cerebral palsy. Dev Med Child Neurol 2018;60:839-845.

Gates, D.H., Walters, L.S., Cowley, J., Wilken, J.M., Resnik, L. Range of Motion Requirements for Upper-Limb Activities of Daily Living. Am J Occup Ther 2016;70:7001350010p1$7001350010 \mathrm{p} 10$.

Hinkle, D.E., Wiersma, W., Jurs, S.G. Applied Statistics for the Behavioral Sciences, 5 edition. ed. Boston: Houghton Mifflin, 2002.

Hung, Y.-C., Charles, J., Gordon, A.M. Bimanual coordination during a goal-directed task in children with hemiplegic cerebral palsy. Developmental Medicine \& Child Neurology 2004;46:746753.

Hung, Y.-C., Henderson, E.R., Akbasheva, F., Valte, L., Ke, W.S., Gordon, A.M. Planning and coordination of a reach-grasp-eat task in children with hemiplegia. Res Dev Disabil 2012;33:1649-1657.

Hung, Y.-C., Spingarn, A. Whole body organization during a symmetric bimanual pick up task for children with unilateral cerebral palsy. Gait \& Posture 2018;64:38-42.

Jaspers, E., Desloovere, K., Bruyninckx, H., Klingels, K., Molenaers, G., Aertbeliën, E., Van Gestel, L., Feys, H. Three-dimensional upper limb movement characteristics in children with hemiplegic cerebral palsy and typically developing children. Res Dev Disabil 2011a;32:22832294. 
Jaspers, E., Desloovere, K., Bruyninckx, H., Molenaers, G., Klingels, K., Feys, H. Review of quantitative measurements of upper limb movements in hemiplegic cerebral palsy. Gait \& Posture 2009;30:395-404.

Jaspers, E., Feys, H., Bruyninckx, H., Cutti, A., Harlaar, J., Molenaers, G., Desloovere, K. The reliability of upper limb kinematics in children with hemiplegic cerebral palsy. Gait \& Posture 2011b;33:568-575.

Jaspers, E., Feys, H., Bruyninckx, H., Harlaar, J., Molenaers, G., Desloovere, K. Upper limb kinematics: Development and reliability of a clinical protocol for children. Gait \& Posture 2011c;33:279-285.

Jaspers, E., Feys, H., Bruyninckx, H., Klingels, K., Molenaers, G., Desloovere, K. The Arm Profile Score: A new summary index to assess upper limb movement pathology. Gait \& Posture 2011d;34:227-233.

Kadaba, M.P., Ramakrishnan, H.K., Wootten, M.E. Measurement of lower extremity kinematics during level walking. J. Orthop. Res. 1990;8:383-392.

Klotz, M., Drongelen, S., Rettig, O., Wenger, P., Gantz, S., Dreher, T., Wolf, S. Motion analysis of the upper extremity in children with unilateral cerebral palsy-An assessment of six daily tasks. Research in Developmental Disabilities 2014;35:2950-2957.

Krumlinde-Sundholm, L., Holmefur, M., Kottorp, A., Eliasson, A.-C. The Assisting Hand Assessment: current evidence of validity, reliability, and responsiveness to change. Developmental Medicine \& Child Neurology 2007;49:259-264.

Lempereur, M., Leboeuf, F., Brochard, S., Rousset, J., Burdin, V., Rémy-Néris, O. In vivo estimation of the glenohumeral joint centre by functional methods: accuracy and repeatability assessment. J Biomech 2010;43:370-374.

Mackey, A.H., Walt, S.E., Stott, N.S. Deficits in Upper-Limb Task Performance in Children With Hemiplegic Cerebral Palsy as Defined by 3-Dimensional Kinematics. Archives of Physical Medicine and Rehabilitation 2006;87, 207-215. https://doi.org/10.1016/j.apmr.2005.10.023

Mailleux, L., Jaspers, E., Ortibus, E., Simon-Martinez, C., Desloovere, K., Molenaers, G., Klingels, K., Feys, H. Clinical assessment and three-dimensional movement analysis: An integrated approach for upper limb evaluation in children with unilateral cerebral palsy. PLOS ONE 2017; 12, e0180196.

Newman, C.J., Bruchez, R., Roches, S., Jequier Gygax, M., Duc, C., Dadashi, F., Massé, F., Aminian, $\mathrm{K}$. Measuring upper limb function in children with hemiparesis with 3D inertial sensors. Childs Nerv Syst 2017;33:2159-2168.

Rudisch, J., Butler, J., Izadi, H., Zielinski, I.M., Aarts, P., Birtles, D., Green, D. Kinematic parameters of hand movement during a disparate bimanual movement task in children with unilateral Cerebral Palsy. Hum Mov Sci 2016;46:239-250.

Schneiberg, S., Mckinley, P., Gisel, E., Sveistrup, H., Levin, M.F. Reliability of kinematic measures of functional reaching in children with cerebral palsy. Developmental Medicine \& Child Neurology 2010;52:e167-e173.

Wu, G., van der Helm, F.C.T., Veeger, H.E.J.D., Makhsous, M., Van Roy, P., Anglin, C., Nagels, J., Karduna, A.R., McQuade, K., Wang, X., Werner, F.W., Buchholz, B., International Society of Biomechanics. ISB recommendation on definitions of joint coordinate systems of various joints for the reporting of human joint motion--Part II: shoulder, elbow, wrist and hand. J Biomech 2005;38:981-992. 


\section{Biography}

Marine Cacioppo is a physical medicine and rehabilitation pediatric physician and researcher. She has her Master's Degree from Rennes University (France) on movement sport and health. Her researches focuses on understanding of impaired upper limb function in children with physical disabilities using motion analysis. She is currently working on assessment of bimanual performance in the context of her PhD, within the research team BE a CHILD ((BrEizh Center for technological innovation And research for CHILDren with Disabilities). 
Table 1 - Description of the five bimanual tasks of BE API 2.0

\begin{tabular}{|c|c|c|c|c|c|c|}
\hline & DoF of interest & Scenario & Movement & $\begin{array}{c}\text { Instructions to the } \\
\text { child }\end{array}$ & $\begin{array}{c}\text { Selected cycle of } \\
\text { movement }\end{array}$ & $\begin{array}{c}\text { Possible } \\
\text { adaptation }\end{array}$ \\
\hline Task 1 & $\begin{array}{l}\text { - elbow extension } \\
\text { - wrist adduction }\end{array}$ & $\begin{array}{l}\text { "Flying over } \\
\text { mountains" } \\
\text { The pilot has to fly } \\
\text { above mountains, } \\
\text { following the summits. }\end{array}$ & $\begin{array}{l}\text { Pushing the wheel down and pulling it back up with both } \\
\text { hands. }\end{array}$ & $\begin{array}{l}\text { "Follow the } \\
\text { mountains summits } \\
\text { by pushing the } \\
\text { wheel down and } \\
\text { pulling it back up, } \\
\text { use both hands on } \\
\text { the wheel" }\end{array}$ & $\begin{array}{l}\text { One cycle= } \\
\text { - Start: grasp the } \\
\text { wheel } \\
\text { - End: when the } \\
\text { wheel touches the } \\
\text { table. }\end{array}$ & None \\
\hline Task 2 & $\begin{array}{l}\text { - shoulder external } \\
\text { rotation }\end{array}$ & $\begin{array}{l}\text { "Slaloming" } \\
\text { The pilot has to slalom } \\
\text { around several wind } \\
\text { turbines and to fly } \\
\text { quickly by putting on } \\
\text { the turbo. }\end{array}$ & $\begin{array}{l}\text { Rotating the wheel with the affected hand (non-dominant) } \\
90^{\circ} \text { upwards then } 90^{\circ} \text { downwards while pressing the turbo } \\
\text { with the dominant hand. }\end{array}$ & $\begin{array}{l}\text { "Press the turbo } \\
\text { with one hand and } \\
\text { turn the wheel right } \\
\text { up and right down } \\
\text { with the other hand, } \\
\text { don't let go of the } \\
\text { wheel and keep } \\
\text { pressing the turbo." }\end{array}$ & $\begin{array}{l}\text { One cycle }= \\
\text { - Start: wheel } \\
\text { rotated } 90^{\circ} \text { upwards } \\
\text { - End: wheel } \\
\text { rotated } 90^{\circ} \\
\text { downwards }\end{array}$ & $\begin{array}{l}\text { The wheel can be } \\
\text { rotated less than } \\
90^{\circ} \text { if the child } \\
\text { cannot keep his/her } \\
\text { hand on the wheel } \\
\text { beyond a certain } \\
\text { range of motion }\end{array}$ \\
\hline Task 3 & $\begin{array}{l}\text { - shoulder } \\
\text { elevation } \\
\text { - humeral plane of } \\
\text { elevation }\end{array}$ & $\begin{array}{l}\text { "Hooking the } \\
\text { luggage" } \\
\text { During a flight in a } \\
\text { storm, the plane door } \\
\text { has opened and } 5 \\
\text { pieces of luggage have } \\
\text { fallen out. The pilot has } \\
\text { to pick up a piece of } \\
\text { luggage (magnetic } \\
\text { image) and stick it to } \\
\text { the top of the } \\
\text { dashboard. The plane } \\
\text { will then locate the }\end{array}$ & $\begin{array}{l}\text { Taking a magnet (one per trial) placed on the table on the } \\
\text { paretic (non-dominant) side ( } 10 \mathrm{~cm} \text { lateral to the hand), and } \\
\text { hanging it on the magnetic dashboard (placed at } 45^{\circ} \text { to a line } \\
\text { emanating from the sternum on the paretic side), as high as } \\
\text { possible. At the same time, the other hand keeps the wheel } \\
\text { horizontal. }\end{array}$ & $\begin{array}{l}\text { "Take a piece of } \\
\text { luggage and place it } \\
\text { as high as possible } \\
\text { on the dashboard, } \\
\text { without standing } \\
\text { up. Keep the wheel } \\
\text { straight with your } \\
\text { other hand" }\end{array}$ & $\begin{array}{l}\text { One cycle }= \\
\text { - Start: grasping the } \\
\text { magnet on the table } \\
\text { - End: magnet hung } \\
\text { on the dashboard. }\end{array}$ & $\begin{array}{l}\text { The magnet can be } \\
\text { stabilized on the } \\
\text { table by the } \\
\text { evaluator to help } \\
\text { the child to grasp it. }\end{array}$ \\
\hline
\end{tabular}




\begin{tabular}{|c|c|c|c|c|c|c|}
\hline & & $\begin{array}{l}\text { luggage and come to } \\
\text { fetch it. }\end{array}$ & & 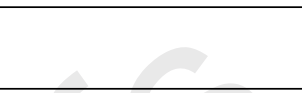 & & \\
\hline Task 4 & - wrist extension & $\begin{array}{l}\text { "Opening the door" } \\
\text { Parachutists are on the } \\
\text { back of the plane ready } \\
\text { to jump, the pilot has to } \\
\text { open the plane door to } \\
\text { drop them. }\end{array}$ & $\begin{array}{l}\text { The child has to pull a shifter towards him/her and then } \\
\text { bring it forward with the affected (non-dominant) hand, } \\
\text { while the other hand keeps the wheel horizontal. }\end{array}$ & $\begin{array}{l}\text { "Open the door to } \\
\text { let the parachutist } \\
\text { out by pulling the } \\
\text { shifter right back. } \\
\text { Hold the wheel } \\
\text { steady with your } \\
\text { other hand". }\end{array}$ & $\begin{array}{l}\text { One cycle= } \\
\text { - Start: the child } \\
\text { grasps the shifter } \\
\text { which is in a } \\
\text { forward position } \\
\text { - End: the shifter is } \\
\text { pulled right back. }\end{array}$ & none \\
\hline Task 5 & - elbow supination & $\begin{array}{l}\text { "Refueling" } \\
\text { To refuel the airplane, } \\
\text { the pilot has to fill the } \\
\text { gas tank. }\end{array}$ & $\begin{array}{l}\text { The child must press the buzzer with the dominant hand. } \\
\text { He/she must then supinate the affected (non-dominant) hand } \\
\text { to catch a gas coin dropped and place it on the gas tank. }\end{array}$ & $\begin{array}{l}\text { "Press the buzzer } \\
\text { with the palm of } \\
\text { your hand and keep } \\
\text { holding it down. I } \\
\text { will drop a coin into } \\
\text { your other hand so } \\
\text { that you can refuel } \\
\text { the airplane - you } \\
\text { will have to turn } \\
\text { your other hand } \\
\text { palm-up to catch } \\
\text { the coin and place it } \\
\text { on the gas tank.." }\end{array}$ & $\begin{array}{l}\text { One cycle }= \\
\text { - Start: forearm and } \\
\text { hand flat on the } \\
\text { table } \\
\text { - End: hand turned } \\
\text { over with gas coin } \\
\text { in palm }\end{array}$ & $\begin{array}{l}\text { If full supination is } \\
\text { not possible, the } \\
\text { child turns his/her } \\
\text { hand as much as } \\
\text { possible and the } \\
\text { coin is placed in the } \\
\text { hand by the } \\
\text { assessor. }\end{array}$ \\
\hline
\end{tabular}

The BE-API 2.0 protocol is composed of five bimanual tasks performed successively: task 1 "Flying over mountain summits", task 2 "Slaloming", task 3 "Hooking the luggage on dashboard" and task 4 "Opening the door". Each task represents a flying mission in order to become an airplane pilot. Between each flying mission, task 5 "Refuelling" is carried out to "refuel the airplane".

The starting position for each task was upright sitting on an adjustable chair with $90^{\circ}$ of hip, knee and elbow flexion. The forearm and hand were placed on the table. 
Table 2: Comparison of joint angles, smoothness and trajectory straightness variables between children with uCP and TDC for each task of the BE-API 2.0

\begin{tabular}{|c|c|c|c|c|c|c|c|c|}
\hline & & \multicolumn{3}{|c|}{ Joint angle variables } & \multicolumn{4}{|c|}{$\begin{array}{c}\text { Smoothness and straightness trajectory } \\
\text { variables }\end{array}$} \\
\hline & \multirow{2}{*}{ DoF } & $\begin{array}{c}\mathrm{uCP} \\
(\mathrm{n}=19)\end{array}$ & $\begin{array}{c}\text { TDC } \\
(n=20)\end{array}$ & & & $\begin{array}{c}\mathrm{uCP} \\
(\mathrm{n}=19)\end{array}$ & $\begin{array}{c}\text { TDC } \\
(\mathrm{n}=20)\end{array}$ & \\
\hline & & $\begin{array}{c}\text { Mean }\left({ }^{\circ}\right) \\
{[\mathrm{SD}]}\end{array}$ & $\begin{array}{c}\text { Mean }\left({ }^{\circ}\right) \\
{[\mathrm{SD}]}\end{array}$ & $\begin{array}{c}\mathrm{p}^{*} \\
{[95 \% \mathrm{CI}]}\end{array}$ & & Mean [SD] & Mean [SD] & $\begin{array}{c}\mathrm{p}^{*} \\
{[95 \% \mathrm{CI}]}\end{array}$ \\
\hline \multirow[t]{4}{*}{$\begin{array}{c}\text { Task } \\
1\end{array}$} & MAX Elbow Ext & $\begin{array}{l}-56.39 \\
{[14.79]}\end{array}$ & $\begin{array}{l}-38.66 \\
{[6.84]}\end{array}$ & $<0.001$ & \multirow{4}{*}{ SPARC } & \multirow{4}{*}{$\begin{array}{l}-1.65 \\
{[0.12]}\end{array}$} & \multirow{4}{*}{$\begin{array}{l}-1.63 \\
{[0.10]}\end{array}$} & \multirow{4}{*}{0.75} \\
\hline & RoM Elbow FE & $\begin{array}{c}36.4 \\
{[9.89]}\end{array}$ & $\begin{array}{c}43.83 \\
{[12.51]}\end{array}$ & 0.04 & & & & \\
\hline & MAX Wrist Add & $\begin{array}{l}24,97 \\
{[6.47]}\end{array}$ & $\begin{array}{l}26,79 \\
{[3.88]}\end{array}$ & 0.70 & & & & \\
\hline & RoM Wrist Abd-Add & $\begin{array}{l}16,29 \\
{[8.53]}\end{array}$ & $\begin{array}{l}23,98 \\
{[4.59]}\end{array}$ & $<0.01$ & & & & \\
\hline \multirow[t]{2}{*}{$\begin{array}{c}\text { Task } \\
2\end{array}$} & MAX Shoulder ER & $\begin{array}{c}52.43 \\
{[16.25]}\end{array}$ & $\begin{array}{c}59.15 \\
{[13.91]}\end{array}$ & 0.16 & \multirow[t]{2}{*}{ SPARC } & \multirow{2}{*}{$\begin{array}{l}-1.67 \\
{[0.22]}\end{array}$} & \multirow{2}{*}{$\begin{array}{l}-1.56 \\
{[0.07]}\end{array}$} & \multirow[t]{2}{*}{0.12} \\
\hline & RoM Shoulder Rot & $\begin{array}{c}25.89 \\
{[13.23]}\end{array}$ & $\begin{array}{c}33.21 \\
{[11.55]}\end{array}$ & 0.23 & & & & \\
\hline \multirow[t]{4}{*}{$\begin{array}{c}\text { Task } \\
3\end{array}$} & $\begin{array}{l}\text { MAX Shoulder } \\
\text { Elevation }\end{array}$ & $\begin{array}{l}112.17 \\
{[10.86]}\end{array}$ & $\begin{array}{l}118.65 \\
{[6.45]}\end{array}$ & 0.72 & \multirow{4}{*}{ SPARC } & \multirow{4}{*}{$\begin{array}{c}-1.55 \\
{[0.18]} \\
\\
1.25 \\
{[0.26]}\end{array}$} & \multirow{4}{*}{$\begin{array}{c}-1.46 \\
{[0.06]} \\
\\
1.11 \\
{[0.07]}\end{array}$} & \multirow[b]{2}{*}{0.04} \\
\hline & $\begin{array}{l}\text { RoM Shoulder } \\
\text { Elevation }\end{array}$ & $\begin{array}{c}71.02 \\
{[12.09]}\end{array}$ & $\begin{array}{r}74,37 \\
{[9.78]}\end{array}$ & 0.69 & & & & \\
\hline & $\begin{array}{l}\text { MAX Humeral Plane } \\
\text { of Elevation }\end{array}$ & \multirow[t]{2}{*}{$\begin{array}{l}41.19 \\
{[9.87]}\end{array}$} & \multirow{2}{*}{$\begin{array}{c}33.95 \\
{[6.76]} \\
\\
\\
80.85 \\
{[16.56]}\end{array}$} & \multirow[t]{2}{*}{0.10} & & & & \multirow[t]{2}{*}{0.03} \\
\hline & $\begin{array}{l}\text { RoM Humeral Plane of } \\
\text { Elevation }\end{array}$ & & & & & & & \\
\hline \multirow[t]{2}{*}{$\begin{array}{c}\text { Task } \\
4\end{array}$} & MAX Wrist Ext & $\begin{array}{c}4.98 \\
{[31.49]}\end{array}$ & $\begin{array}{c}37,15 \\
{[10.89]}\end{array}$ & $<0.01$ & \multirow[t]{2}{*}{ SPARC } & \multirow[t]{2}{*}{$\begin{array}{l}-1.57 \\
{[0.12]}\end{array}$} & \multirow[t]{2}{*}{$\begin{array}{l}-1.59 \\
{[0.05]}\end{array}$} & \multirow[t]{2}{*}{0.12} \\
\hline & RoM Wrist FE & $\begin{array}{c}34.89 \\
{[18.63]}\end{array}$ & $\begin{array}{c}50.33 \\
{[12.22]}\end{array}$ & $<0.01$ & & & & \\
\hline \multirow[t]{2}{*}{$\begin{array}{c}\text { Task } \\
5\end{array}$} & MAX Supination & $\begin{array}{c}36.53 \\
{[37.10]}\end{array}$ & $\begin{array}{l}72.15 \\
{[9.65]}\end{array}$ & $<0.0001$ & \multirow{2}{*}{$\begin{array}{c}\text { SPARC } \\
\text { IoC }\end{array}$} & \multirow{2}{*}{$\begin{array}{c}-1.74 \\
{[0.25]} \\
\\
1.79 \\
{[0.71]}\end{array}$} & \multirow{2}{*}{$\begin{array}{c}-1.64 \\
{[0.17]} \\
\\
1.94 \\
{[1.28]}\end{array}$} & 0.22 \\
\hline & $\begin{array}{l}\text { RoM Pronation- } \\
\text { supination }\end{array}$ & $\begin{array}{l}80.91 \\
{[34.0]}\end{array}$ & $\begin{array}{c}113.62 \\
{[12.16]}\end{array}$ & $<0.01$ & & & & 0.45 \\
\hline
\end{tabular}

Means and Standard Deviations [SD] of maximum angle value (MAX), Range of Motion (RoM), Spectral arc length (SPARC) and Index of Curvature (IoC) values are presented. Comparisons between children with unilateral Cerebral Palsy (uCP) and Typically Developing Children (TDC) were performed using a repeated measures ANOVA (mixed model) based on ranks $(*)$.

AA: Abduction-adduction; DoF: Degree of Freedom; Ext: Extension; ER: External Rotation; FE: FlexionExtension; Rot: Rotation. 
Table 3: Within and between-session reliability of joint angle values for each BE-API 2.0 task.

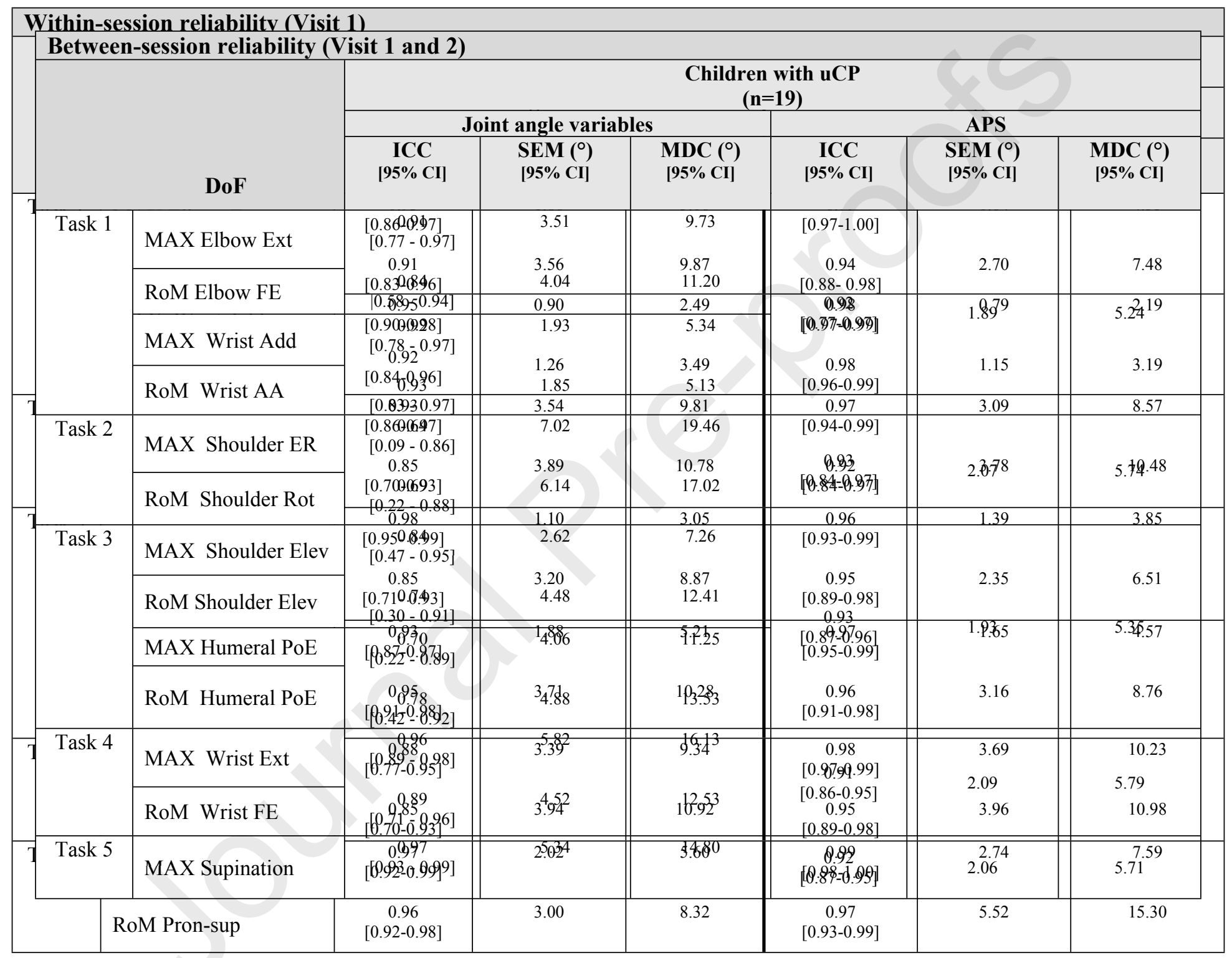




\begin{tabular}{|l|l|c|c|c|c|c|c|}
\hline & RoM Pron-sup & $\begin{array}{c}0.97 \\
{[0.93-0.99]}\end{array}$ & 4.77 & 13.22 & & & \\
\hline
\end{tabular}

Values are mean Coefficient of Multiple Correlation (CMC), intraclass coefficient of correlation (ICC), Standard Error of Measurement (SEM) and Minimal Detectable Change (MDC) with 95\% Confidence Interval [95\% CI].

AA: Abduction-adduction; APS: Arm Profil Score; DoF: Degree of Freedom; Elev: Elevation; Ext: Extension; FE: Flexion-Extension; MAX: Maximal angular values; PoE: Plan of Elevation; Pron-sup: Pronation-supination; RoM: Range of motion; Rot: Rotation; ER: External Rotation; uCP: unilateral Cerebral Palsy. 
Table 4: Within and between-session reliability of SPARC and IoC for each BE-API 2.0 task

\begin{tabular}{|c|c|c|c|c|c|c|c|c|c|}
\hline \multicolumn{7}{|c|}{ Within-session reliability (Visit 1) } & \multirow{2}{*}{\multicolumn{3}{|c|}{$\begin{array}{c}\text { Between-session reliability (Visit } 1 \text { and 2) } \\
\begin{array}{c}\text { Children with } \mathrm{UCP} \\
(\mathrm{n}=19)\end{array} \\
\end{array}$}} \\
\hline & \multicolumn{3}{|c|}{$\begin{array}{c}\text { Typically Developing Children } \\
(\mathrm{n}=\mathbf{2 0})\end{array}$} & \multicolumn{3}{|c|}{$\begin{array}{c}\begin{array}{c}\text { Children with uCP } \\
(\mathrm{n}=19)\end{array} \\
\end{array}$} & & & \\
\hline & $\begin{array}{c}\text { ICC } \\
{[95 \% \mathrm{CI}]}\end{array}$ & $\begin{array}{c}\text { SEM } \\
{[95 \% \mathrm{CI}]}\end{array}$ & $\begin{array}{c}\text { MDC } \\
{[95 \% \mathrm{CI}]}\end{array}$ & $\begin{array}{c}\text { ICC } \\
{[95 \% \mathrm{CI}]}\end{array}$ & 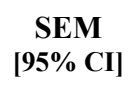 & $\underset{[95 \% \mathrm{CI}]}{\text { MDC }}$ & $\begin{array}{c}\text { ICC } \\
{[95 \% \mathrm{CI}]}\end{array}$ & $\begin{array}{c}\text { SEM } \\
{[95 \% \mathrm{CI}]}\end{array}$ & $\begin{array}{c}\text { MDC } \\
{[95 \% \mathrm{CI}]}\end{array}$ \\
\hline \multicolumn{10}{|c|}{ SPARC } \\
\hline Task 1 & $\begin{array}{c}0.72 \\
{[0.46-0.87]}\end{array}$ & 0.11 & 0.30 & $\begin{array}{c}0.72 \\
{[0.43-0.88]}\end{array}$ & 0.13 & 0.36 & $\begin{array}{c}0.13 \\
{[0-0.66]}\end{array}$ & 0.10 & 0.28 \\
\hline Task 2 & $\begin{array}{c}0.53 \\
{[0.07-0.80]}\end{array}$ & 0.10 & 0.28 & $\begin{array}{c}0.33 \\
{[0-0.72]}\end{array}$ & 0.36 & 1.00 & $\begin{array}{l}0.16 \\
{[0-0.66]}\end{array}$ & 0.18 & 0.50 \\
\hline Task 3 & $\begin{array}{c}0,55 \\
{[0.10-0.80]^{*}}\end{array}$ & 0.06 & 0.17 & $\begin{array}{c}0.61 \\
{[0.22-0.83]}\end{array}$ & 0.23 & 0.64 & $\begin{array}{c}0.84 \\
{[0.58-0.94]}\end{array}$ & 0.09 & 0.25 \\
\hline Task 4 & $\begin{array}{c}0.55 \\
{[0.14-0.80]^{*}}\end{array}$ & 0.08 & 0.22 & $\begin{array}{c}0.76 \\
{[0.53-0.90]}\end{array}$ & 0.12 & 0.33 & $\begin{array}{c}0.57 \\
{[0-0.84]}\end{array}$ & 0.09 & 0.25 \\
\hline Task 5 & $\begin{array}{c}0.31 \\
{[-0.35-0.70]}\end{array}$ & 0.29 & 0.80 & $\begin{array}{c}0.41 \\
{[0-0.75]}\end{array}$ & 0.39 & 1.08 & $\begin{array}{c}0,74 \\
{[0.36-0.90]^{*}}\end{array}$ & 0.13 & 0.36 \\
\hline \multicolumn{10}{|c|}{ IOC } \\
\hline Task 3 & $\begin{array}{c}0.63 \\
{[0.28-0.84]}\end{array}$ & 0.08 & 0.22 & $\begin{array}{c}0.77 \\
{[0.54-0.90]}\end{array}$ & 0.25 & 0.69 & $\begin{array}{c}0.61 \\
{[0-0.85]}\end{array}$ & 0.16 & 0.44 \\
\hline Task 5 & $\begin{array}{c}0.60 \\
{[0.23-0.82]}\end{array}$ & 1.63 & 4.52 & $\begin{array}{c}0.62 \\
{[0.26-0.84]}\end{array}$ & 0.88 & 2.44 & $\begin{array}{c}0.73 \\
{[0.33-0.90]}\end{array}$ & 0.44 & 1.22 \\
\hline
\end{tabular}

Values are mean intraclass coefficients of correlation (ICC), Standard Error of Measurement (SEM) and Minimal Detectable Change (MDC) with 95\% Confidence Intervals $[95 \% \mathrm{CI}]$.

* Statistical analysis was not applicable for the ICC if SPARC values below -2 were included. Therefore, SPARC values below -2 were considered as outliers and excluded from the analysis. These results were not integrated in the interpretation of the overall results.

IoC: Index of Curvature; SPARC: Spectral Arc length; uCP: unilateral CerebrabPalsy. 
Figure 1: All range of motion values for children with uCP and TDC

DoF of interest defined before the study are framed.

AA: Abduction-adduction; DoF: Degree of Freedom; EL: Elevation; FE: Flexion-Extension; IER: InternalExternal Rotation; PoE: Plane of Elevation; PS: Pronation-Supination; TDC: typically developing children; uCP: unilateral Cerebral Palsy 
Figure 1

Task 1 "Flying over mountains"
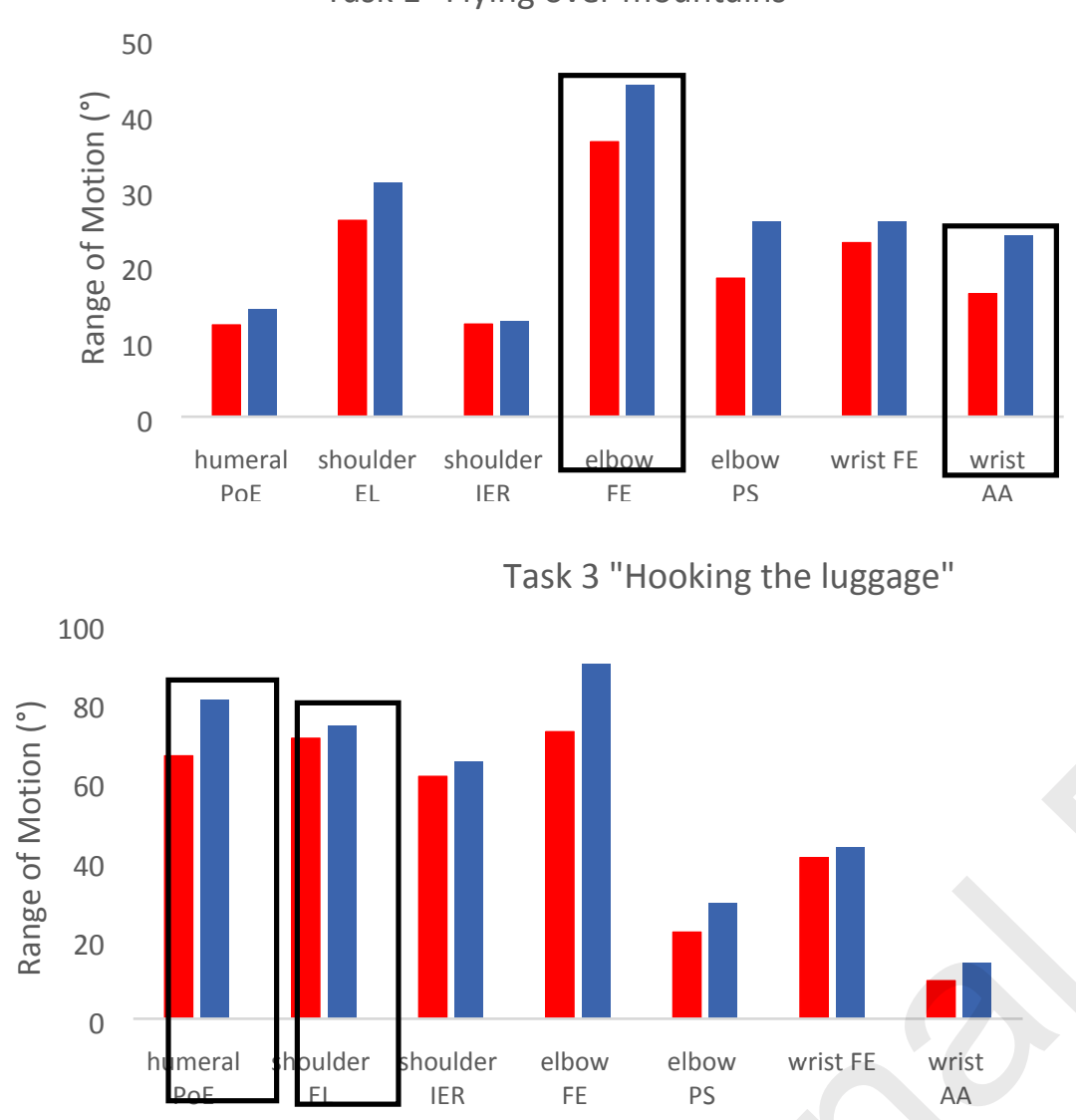

140

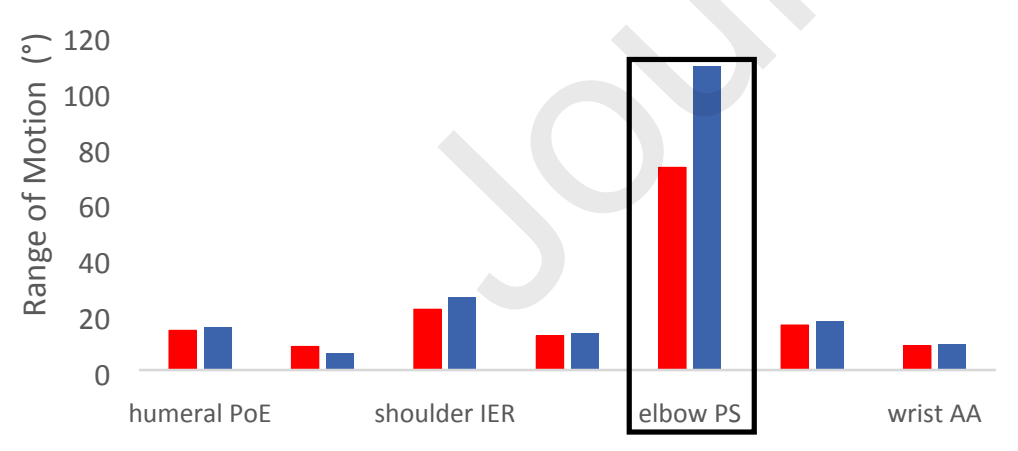

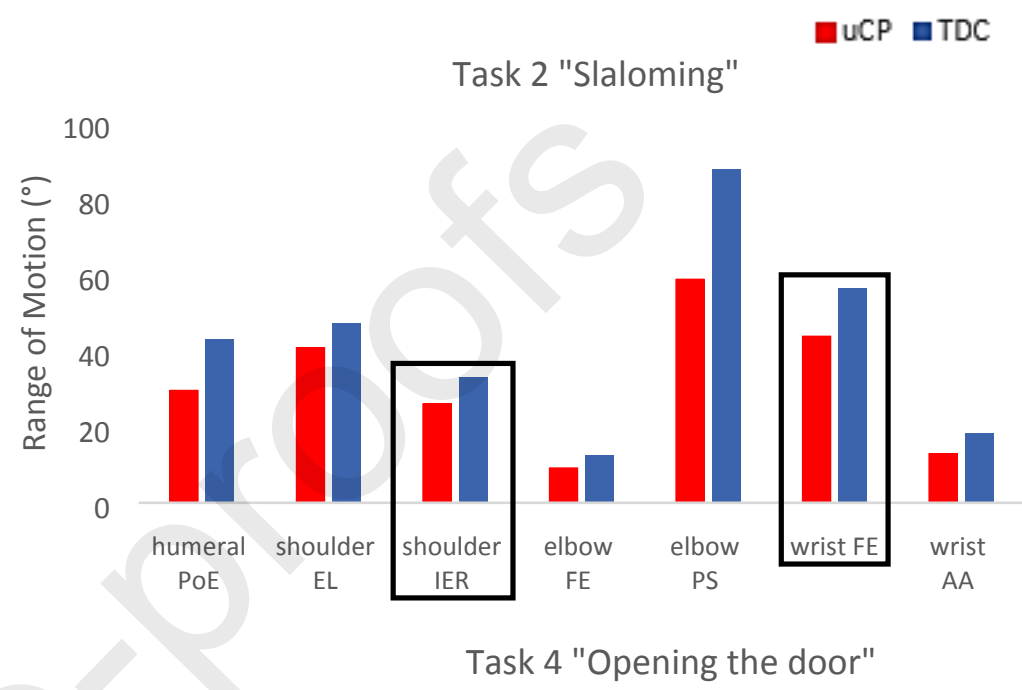

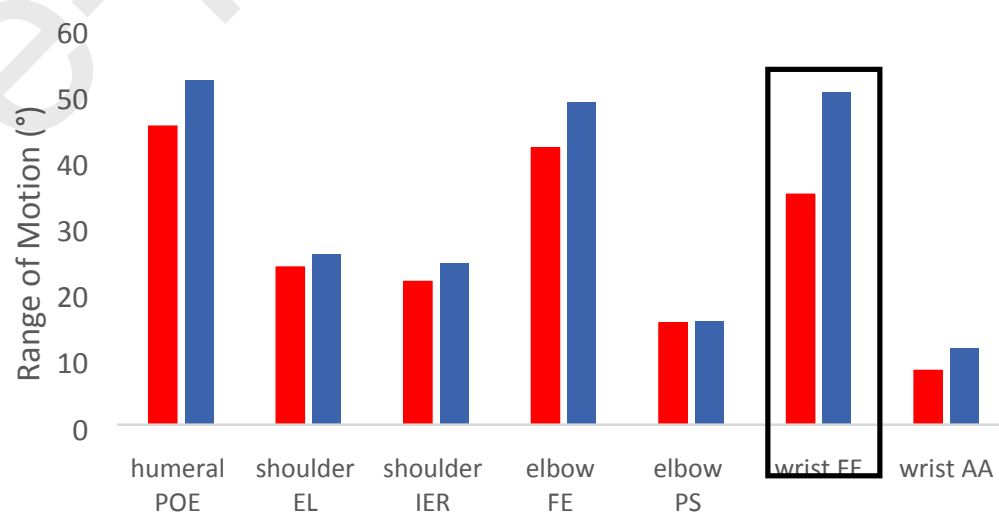

